\title{
Perancangan Sistem Informasi Pengarsipan Di Polsek Rancaekek
}

\author{
${ }^{1}$ Rudi Permana, ${ }^{2}$ Kuwat Santoso \\ Program Studi Sistem Informasi \\ STKOM Al Ma'soem, J1. Raya Cipacing No.22, Cipacing, Jatinangor, Bandung Timur, Jawa Barat 45363 \\ Indonesia \\ email : ${ }^{1}$ rhudiepermana@gmail.com, ${ }^{2}$ kuwat.santoso84@gmail.com
}

\begin{abstract}
Berdasarkan hasil penelitian penulis, ditemukan beberapa permasalahan yang sering terjadi dalam pengarsipan saat ini yaitu kesulitan dalam pencarian surat, terjadinya kehilangan atau kerusakan data, serta sulitnya membuat laporan jika sewaktu-waktu diperlukan. Dilihat dari permasalahan diatas maka dibutuhkan program aplikasi untuk mengatasi masalah tersebut. Metode yang digunakan untuk menganalisa dan merancang sistem informasi pengarsipan ini adalah metode System Development Life Cycle (SDLC). Adapun implementasi dan perancangan yang penulis gunakan yaitu dengan menggunakan Flow Map, Data Flow Diagram, Structure Chart, Diagram E-R, Flow Chart, dan menggunakan bahasa pemograman Visual Studio 2010 serta Microsoft Access 2010 sebagai databasenya.

Perancangan sistem informasi pengarsipan ini diharapkan dapat memudahkan Kepala Seksi Umum (Kasium) dalam melaksanakan pekerjaan pengarsipan seperti pencarian data arsip, mengantisipasi terjadinya kerusakan dan kehilangan data, serta memudahkan dalam membuat laporan jika sewaktu-waktu diperlukan.
\end{abstract}

Kata Kunci : Arsip, Surat Masuk, Disposisi, Surat Keluar, Sistem Informasi, Waterfall, Data Flow Diagram, Flow Map, Structure Chart, Database, Visual Studio 2010

\section{Introduction}

Seiring dengan perkembangan Teknologi Infiormasi (TI) yang semakin pesat terutama Teknologi Informasi Komputer, komputer pada masa sekarang bukan merupakan barang yang asing dan mahal lagi. Hampir semua bidang pekerjaan membutuhkan komputer sebagai alat bantu untuk menyelesaikan pekerjaan dengan kelebihan diantaranya kecepatan, keakuratan, serta keefisienan dalam pengolahan data bila dibandingkan dengan pengolahan data secara manual.

Polisi Sektor Rancaaekek (Polsek Rancaekek) yang beralamatkan di Jl. Rancaekek-Majalaya No. 368 Rancaekek Kab. Bandung memiliki kendala dalam sistem pengarsipan surat masuk dan surat keluar. Frekuensi surat masuk dan surat keluar pada setiap harinya mencapai lima sampai sepuluh surat. Surat masuk terdiri dari surat perijinan, surat keluhan, surat pemberitahuan, surat rekomendasi, surat perintah, dan sebagainya. Sedangkan surat keluar terdiri dari surat ijin, surat perintah, surat anggaran, surat penangkapan, dan sebagainya. Selama ini, pengelolaan arsip di Polsek Rancaekek masih dilakukan dengan cara yang manual, yaitu surat masuk dicatat oleh bagian Kepala Seksi Umum (Kasium) dalam buku surat masuk, kemudian disampaikan ke Kepala Kepolisian Sektor (Kapolsek) untuk dibuatkan disposisi. Jika surat tersebut perlu ditindak lanjuti, maka surat tersebut di salin, kemudian yang aslinya diberikan kepada Satuan Kerja (selanjutnya disingkat Satker) atau penerima surat dan salinannya diarsipkan. Begitu pula surat keluar, setelah dilakukan pencatatan dalam buku surat keluar, surat tersebut di cetak sebanyak dua lembar, satu lembar di kirim kepada tujuan dan satu lembar diarsipkan dalam lemari arsip.

Berdasarkan latar belakang yang telah diuraikan sebelumnya, diantaranya kesulitan dalam pencarian surat masuk, disposisi dan surat keluar. Proses manual beresiko terjadinya kerusakan dan kehilangan data. Kesulitan dalam membuat laporan jika sewaktu-waktu diperlukan. Ruang lingkup yang 
akan dibahas dalam Tugas Akhir ini berkaitan dengan pengarsipan surat masuk dan surat keluar di Polsek Rancaekek. Untuk mempermudah dalam perancangannya, penulis membatasi masalah diantaranya : Sistem surat masuk, Sistem surat keluar, Sistem disposisi. Maksud dari penelitian ini adalah untuk membangun sebuah sistem informasi pengarsipan yang teratur dan terarah dalam penyimpanan dan pencarian arsip. Tujuan lainya yaitu untuk memudahkan dalam pencarian data arsip, antisipasi terjadinya kerusakan dan kehilangan data serta memudahkan dalam membuat laporan jika sewaktu-waktu diperlukan

\section{Research Method}

\subsection{Metode Perancangan Sistem}

Dalam metode perancangan sistem terdapat dua metode pendekatan dalam membangun suatu rancangan sistem, yaitu:

1. Top-Down (Pendekatan atas ke bawah), Pendekatan dimulai dari level atas organisasi, yaitu level perencanaan strategi. Pendekatan ini dimulai dengan mendefinisikan sasaran dan kebijaksanaan organisasi. Selanjutnya dilakukan analisis kebutuhan informasi. Setelah kebutuhan informasi dilakukan, maka dilakukan pemrosesan transaksi yaitu penentuan output, input basis data, dan prosedur-prosedur operasi kontrol.

2. Bottom-Up (Pendekatan bawah ke atas), Pendekatan dimulai dari level bawah organisasi, yaitu level operasional dimana transaksi dilakukan. Pendekatan ini dimulai dari perumusan kebutuhankebutuhan untuk menangani transaksi dan naik ke level atas dengan merumuskan informasi berdasarkan transaksi tersebut.

\subsection{Siklus Hidup Pengembangan Sistem Informasi}

Proses pengembangan sistem melewati beberapa tahapan mulai dari sistem itu direncanakan sampai dengan sistem tersebut diterapkan. Berikut digambarkan Metode Waterfall dimana metode ini meliputi beberapa tahapan yang dapat dilihat pada gambar 1 .

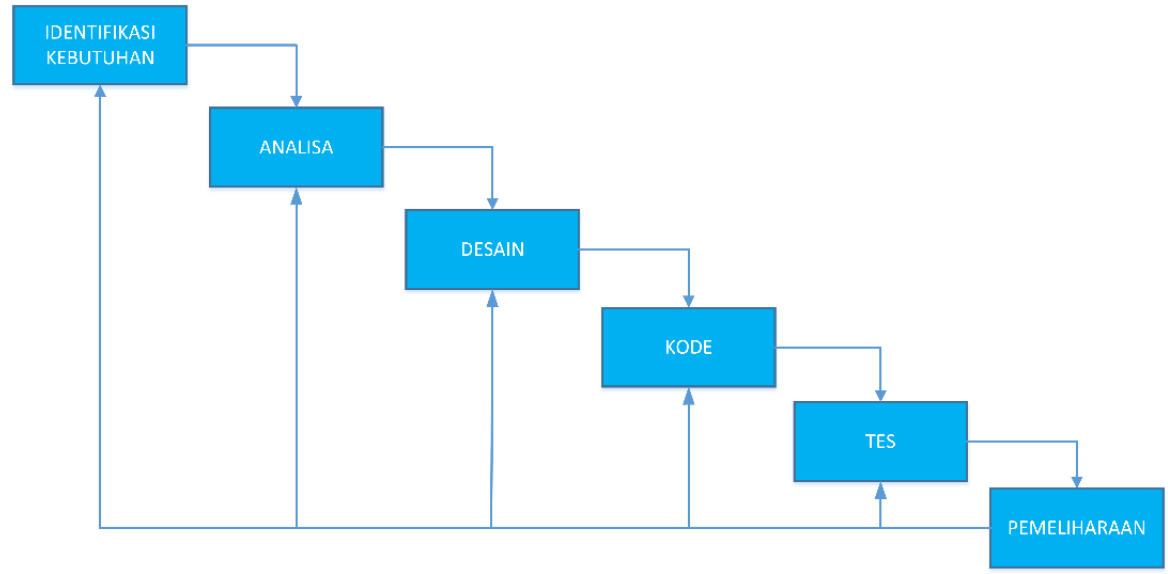

Gambar 1. Siklus Hidup Pengembangan sistem

\subsection{Perangkat Pengembangan Sistem}

Pengembangan sistem merupakan kegiatan yang bertujuan mengembangkan atau memperbaiki sistem yang lama menjadi sistem yang baru. Alasan dilakukannya pengembangan sistem yaitu karena adanya permasalahan-permasalahan yang timbul pada sistem yang lama seperti ketidakselesaian pekerjaan dan pertumbuhan organisasi, untuk meraih kesempatan dan adanya instruksi-instruksi. Pengembangan sistem dapat dilakukan melalui siklus hidup pengembangan sistem atau System Development Life Cycle (SDLC).. 


\section{Result and Analysis}

\subsection{Flow Map Pengarsipan Surat Masuk dan Disposisi}

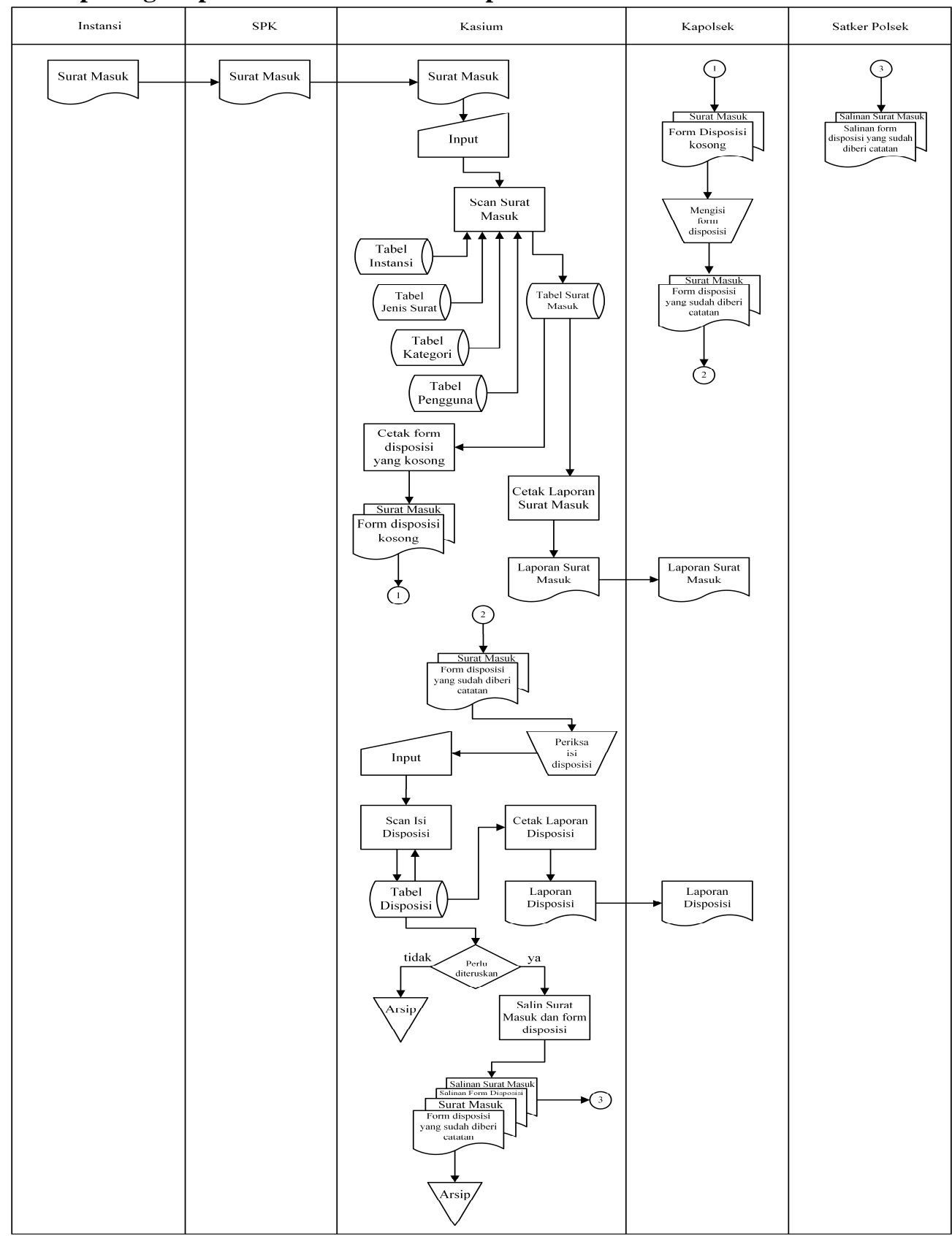

Gambar 2. Flow Map Pengarsipan Surat Masuk dan Diposisi 


\subsection{Flow Map Pengarsipan Surat Keluar}

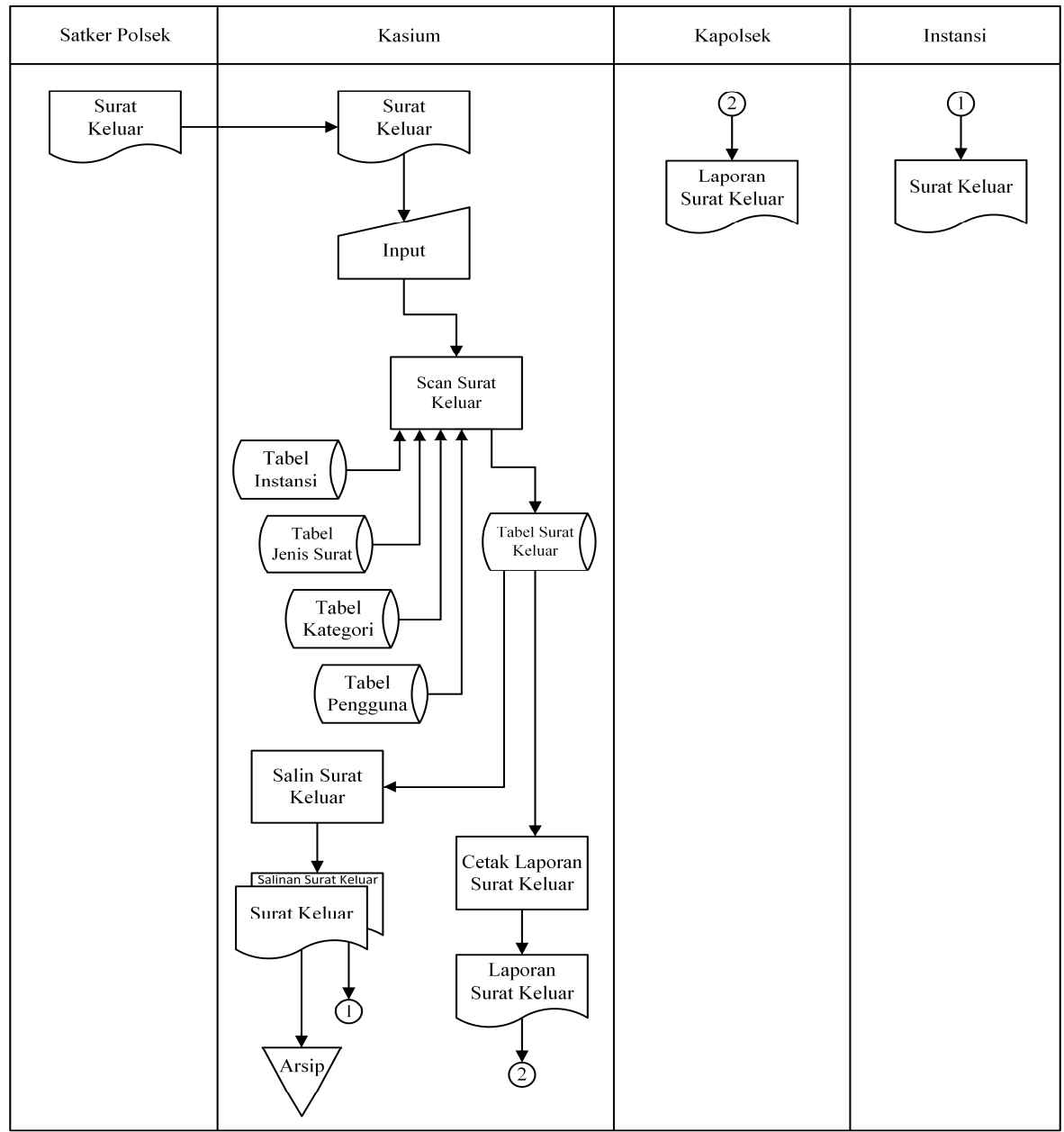

Gambar 3 Flow Map Pengarsipan Surat Keluar

\subsection{Kebutuhan Informasi}

Dalam perancangan aplikasi ini dibutuhkan informasi-informasi yang terkait dengan proses pengarsipan surat masuk, disposisi dan surat keluar di Polsek Rancaekek. Informasi tersebut dapat dilihat pada tabel 1 .

Tabel 1. Kebutuhan Informasi

\begin{tabular}{|c|l|l|l|}
\hline No & \multicolumn{1}{|c|}{ Informasi } & \multicolumn{1}{c|}{ Tujuan } & \multicolumn{1}{c|}{ Frekuensi } \\
\hline 1 & Laporan Surat Masuk & Kapolsek dan Satker Polsek & Bila sewaktu-waktu diperlukan \\
\hline 2 & Laporan Disposisi & Kapolsek dan Satker Polsek & Bila sewaktu-waktu diperlukan \\
\hline 3 & Laporan Surat Keluar & Kasium dan Kapolsek & Bila sewaktu-waktu diperlukan \\
\hline
\end{tabular}

\subsection{Deskripsi Kebutuhan Fungsional}

Deskripsi kebutuhan fungsional yaitu kebutuhan-kebutuhan yang ada biasanya dengan proses pengolahan data, meliputi:

Tabel 2. Deskripsi Kebutuhan Fungsional

\begin{tabular}{|c|l|l|}
\hline No & \multicolumn{1}{|c|}{ Kode Program } & \multicolumn{1}{c|}{ Deskripsi } \\
\hline 1 & FM-1.0 & Kelola Data Master \\
\hline 2 & FM-1.1 & Kelola Data Master Instansi \\
\hline
\end{tabular}




\begin{tabular}{|c|l|l|}
\hline 3 & FM-1.2 & Kelola Data Master Jenis Surat \\
\hline 4 & FM-1.3 & Kelola Data Master Kategori \\
\hline 5 & FM-1.4 & Kelola Data Master Pengguna \\
\hline 6 & FT-2.0 & Kelola Transaksi \\
\hline 7 & FT-2.1 & Kelola Transaksi Surat Masuk \\
\hline 8 & FT-2.2 & Kelola Transaksi Disposisi \\
\hline 9 & FT-2.3 & Kelola Transaksi Surat Keluar \\
\hline 10 & FL-3.0 & Kelola Laporan \\
\hline 11 & FL-3.1 & Kelola Laporan Surat Masuk \\
\hline 12 & FL-3.2 & Kelola Laporan Disposisi \\
\hline 13 & FL-3.3 & Kelola Laporan Surat Keluar \\
\hline 14 & FU-4.0 & Kelola Utilitas \\
\hline 15 & FU-4.2 & Kelola Utilitas Ganti Password \\
\hline
\end{tabular}

\subsection{Contex Diagram}

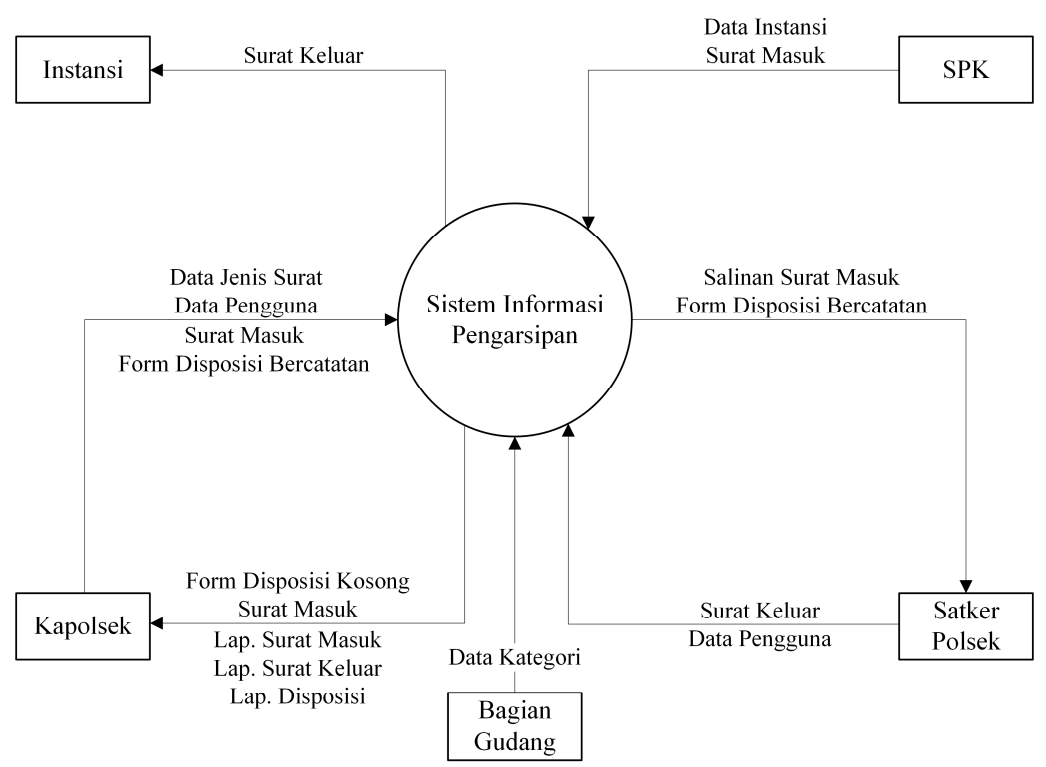

Gambar 4. Contex Diagram 


\subsection{DFD Level 0}

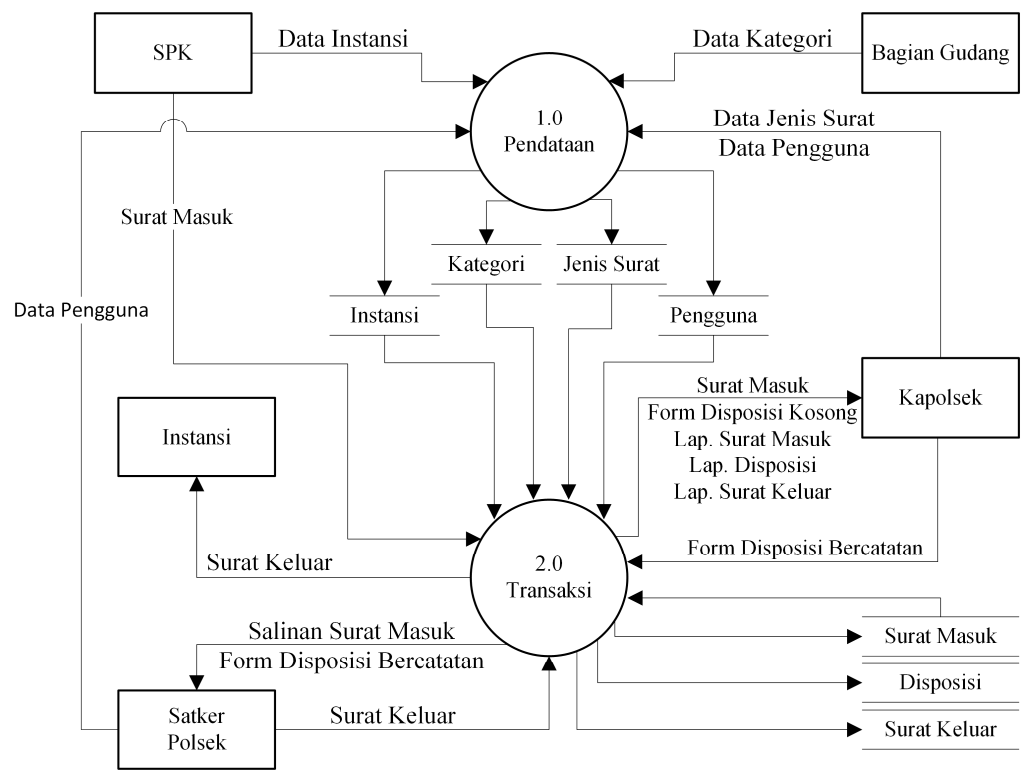

Gambar 5. DFD Level 0

\subsection{DFD Level 1 Proses 0}

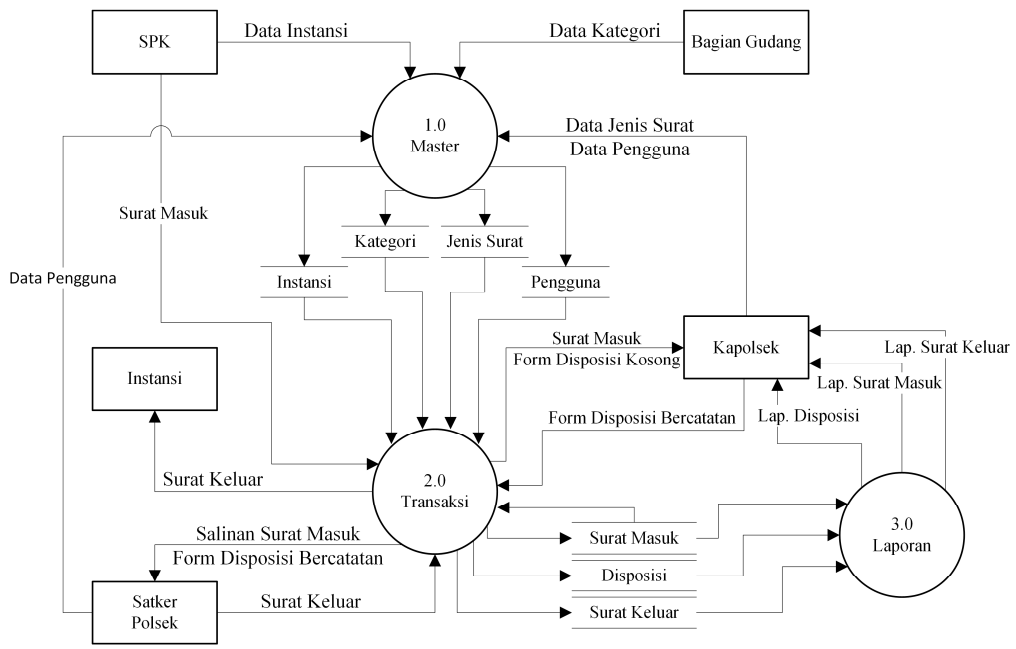

Gambar 6 DFD Level 1 Proses 0 


\subsection{DFD Level 1 Proses 1}

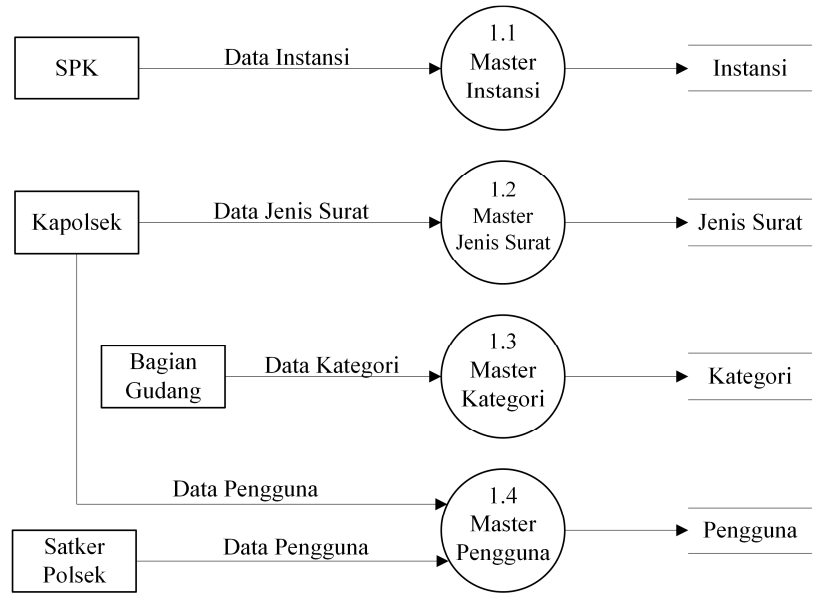

Gambar 7. DFD Level 1 Proses 1

\subsection{DFD Level 1 Proses 2}

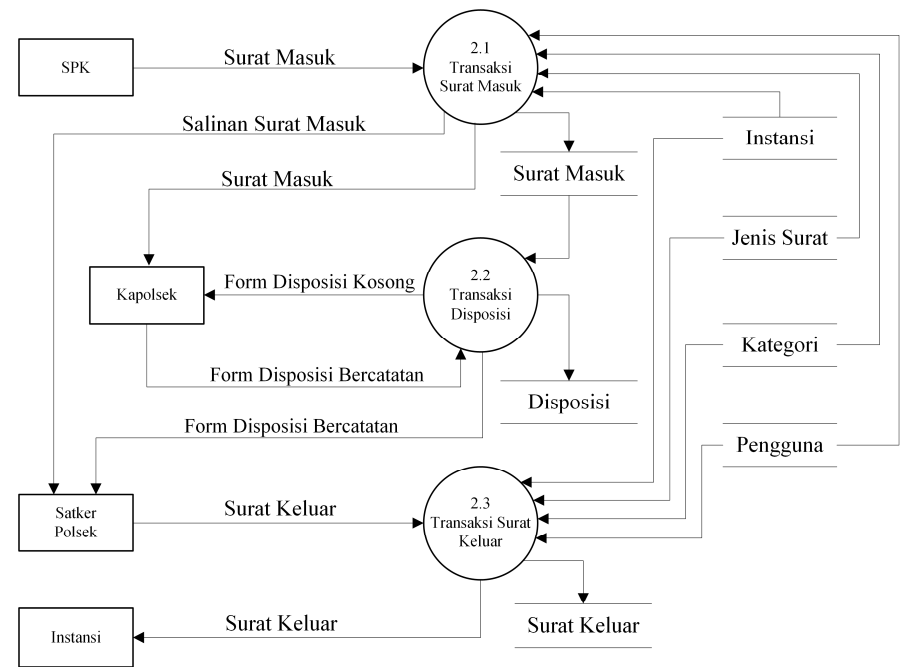

Gambar 8. DFD Level 1 Proses 2

\subsection{DFD Level 1 Proses 3}

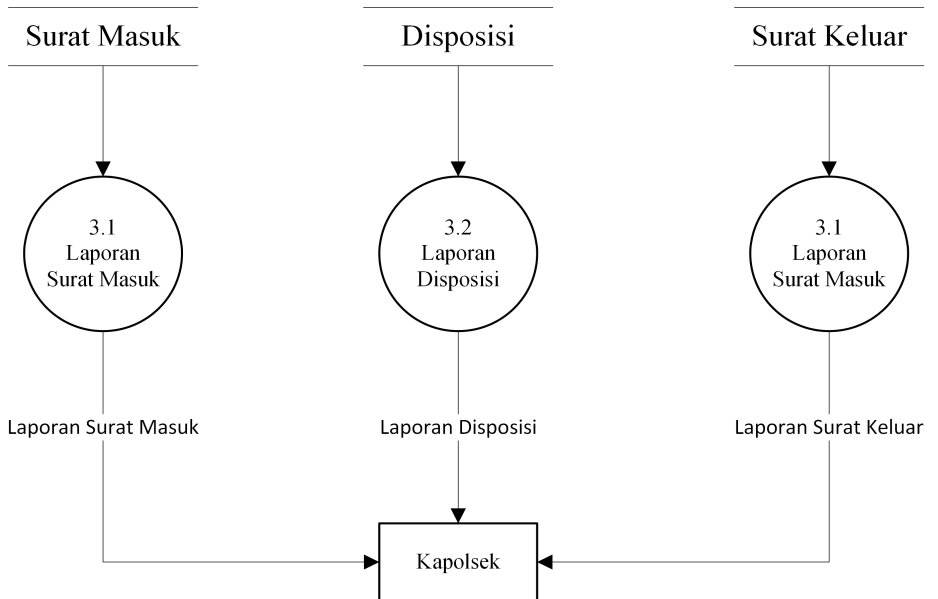

Gambar 3.9 DFD Level 1 Proses 3 


\subsection{Model Data Konseptual Diagram E-R}

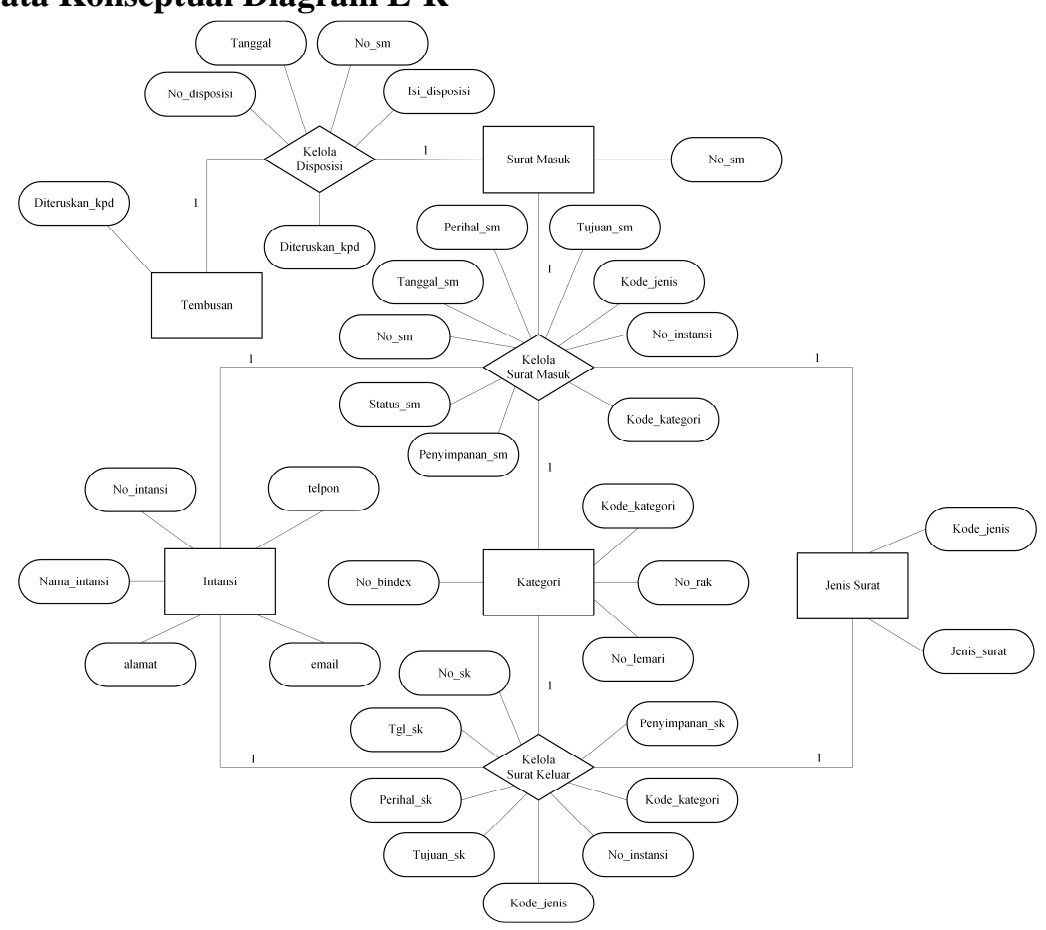

\subsection{Kamus Data}

Gambar 10. Model Data Konseptual Diagram E-R

1. Data Store

a. Instansi = @ no_instansi + nama_instansi + alamat + telpon + email

b. Jenis Surat $=@$ kode_jenis + jenis_surat

c. Kategori $=$ @kode_kategori + nama_kategori + no_rak + no_lemari + no_bindex

d. Surat Masuk $=$ @no_sm + tanggal_sm + perihal_sm + tujuan_sm + kode_jenis + no_instansi + kode_kategori + penyimpanan_sm + status_sm

e. Disposisi = @ no_disposisi + tanggal + no_sm + diteruskan_kpd + isi_disposisi

f. Surat Keluar = @ no_sk + tanggal_sk + perihal_sk + tujuan_sk + kode_jenis + no_instansi + kode_kategori + penyimpanan_sk

2. Arus Data

a. Surat Masuk = @no_sm + tanggal_sm + perihal_sm + tujuan_sm + kode_jenis + no_instansi + kode_kategori

b. Disposisi = @ no_disposisi + tanggal + no_sm + diteruskan_kpd + isi_disposisi

c. Surat Keluar = @no_sk + tanggal_sk + perihal_sk + tujuan_sk + kode_jenis + no_instansi + kode_kategori

\subsection{Skema Relasi Basis Data}

Untuk menjelaskan tentang alur perancangan sistem informasi pengarsipan ini maka di buat skema relasi basis data sebagai berikut: 


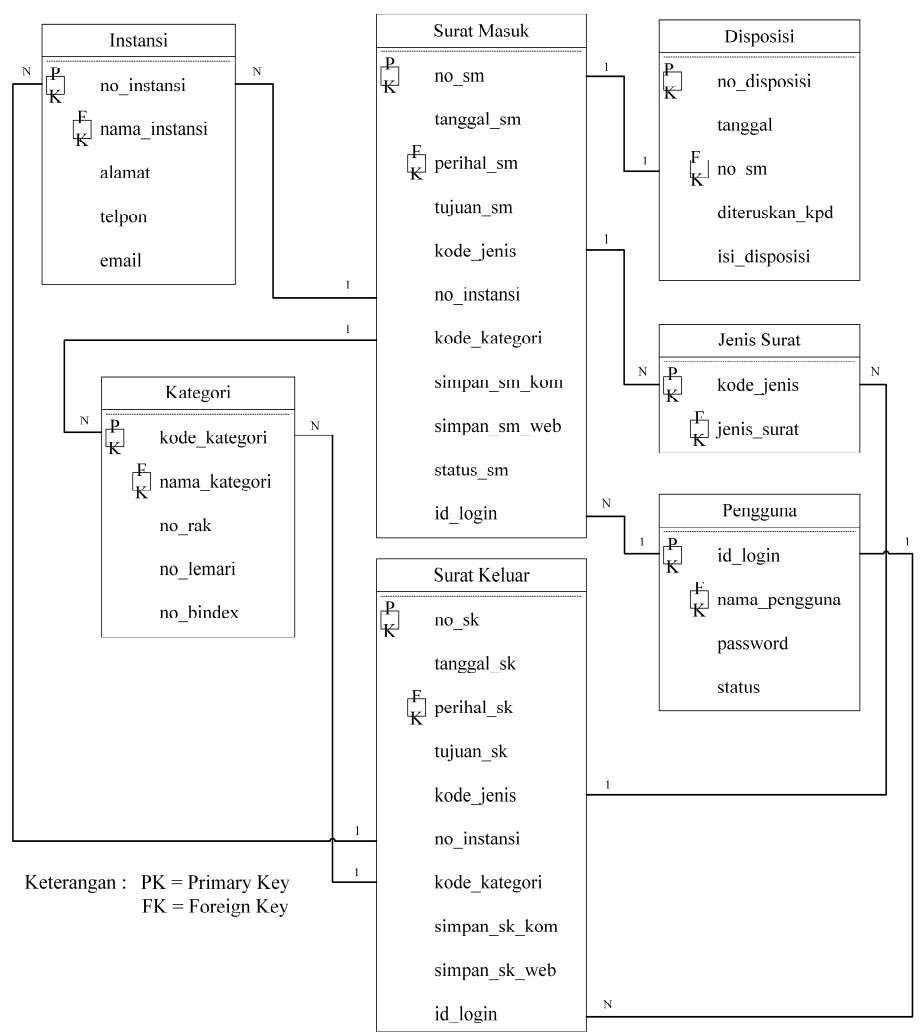

Gambar 11. Skema Relasi Basis Data

\subsection{Structure Chart}

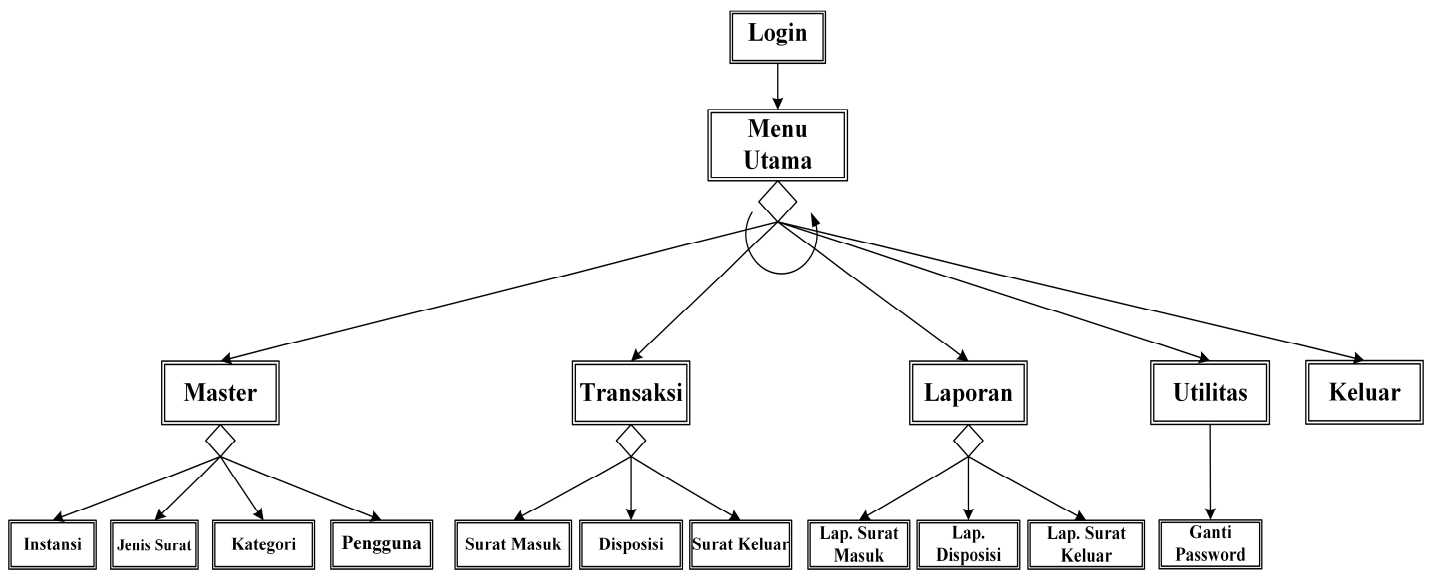

Gambar 12. Structure Chart Sistem Informasi Pengarsipan 


\subsection{Form Login}

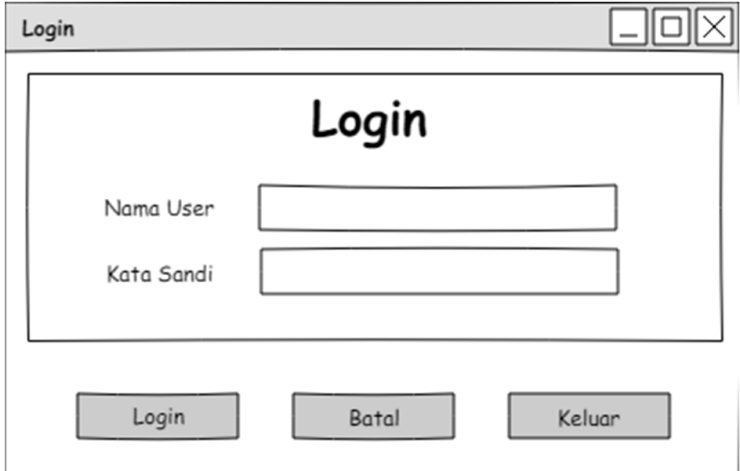

\subsection{Form Menu Utama}

Gambar 13. Form Login

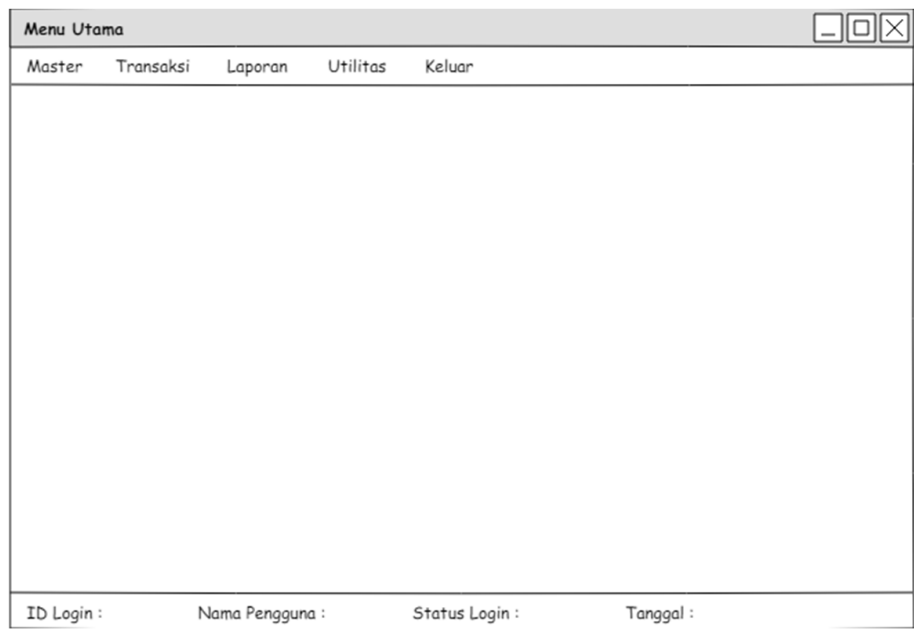

Gambar 14. Form Menu Utama

3.18. Form Master Instansi

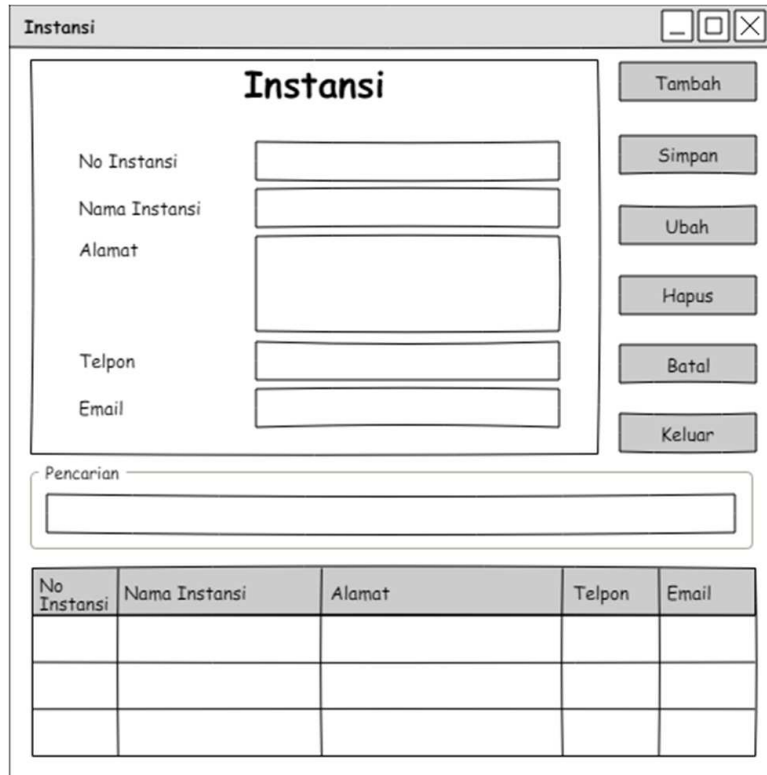

Gambar 15. Form Master Instansi 
3.19. Form Master Kategori

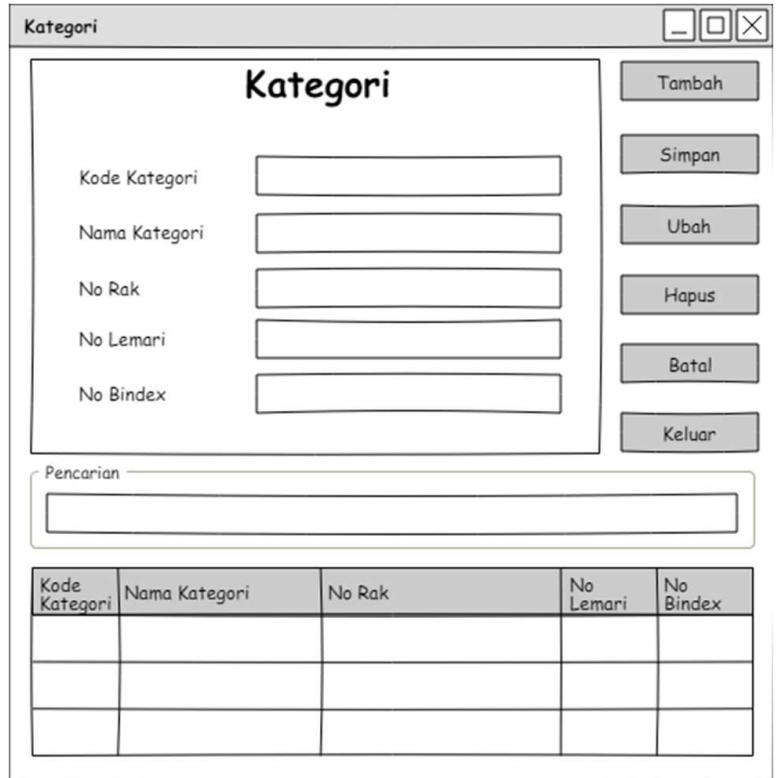

Gambar 16. Form Master Kategori

3.20. Form Master Jenis Surat

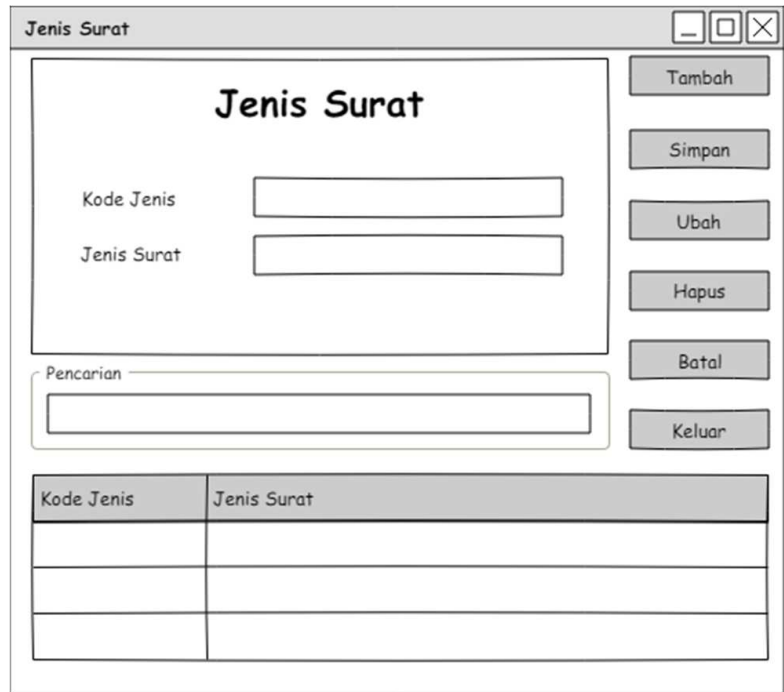

Gambar 17. Form Master Jenis Surat 


\subsection{Form Master Pengguna}

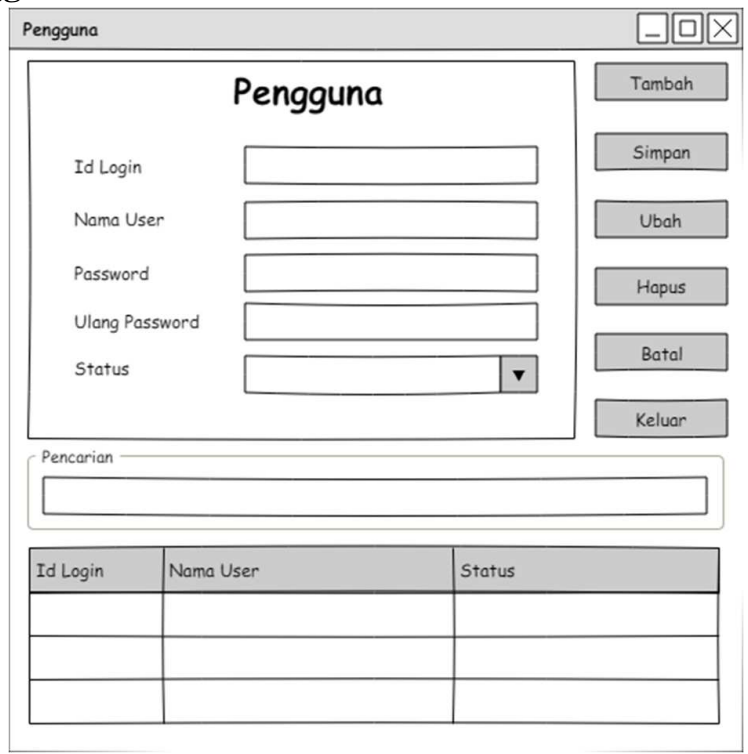

Gambar 18. Form Master Pengguna

3.33. Form Transaksi Surat Masuk

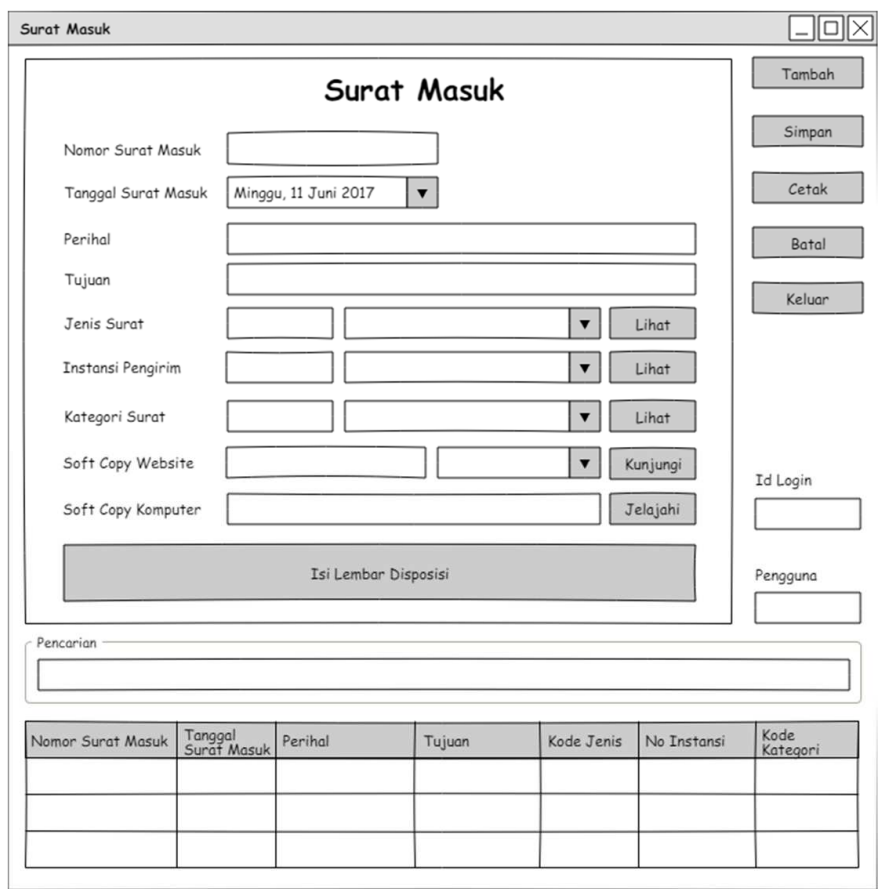

Gambar 19. Form Transaksi Surat Masuk 


\subsection{Form Transaksi Disposisi}

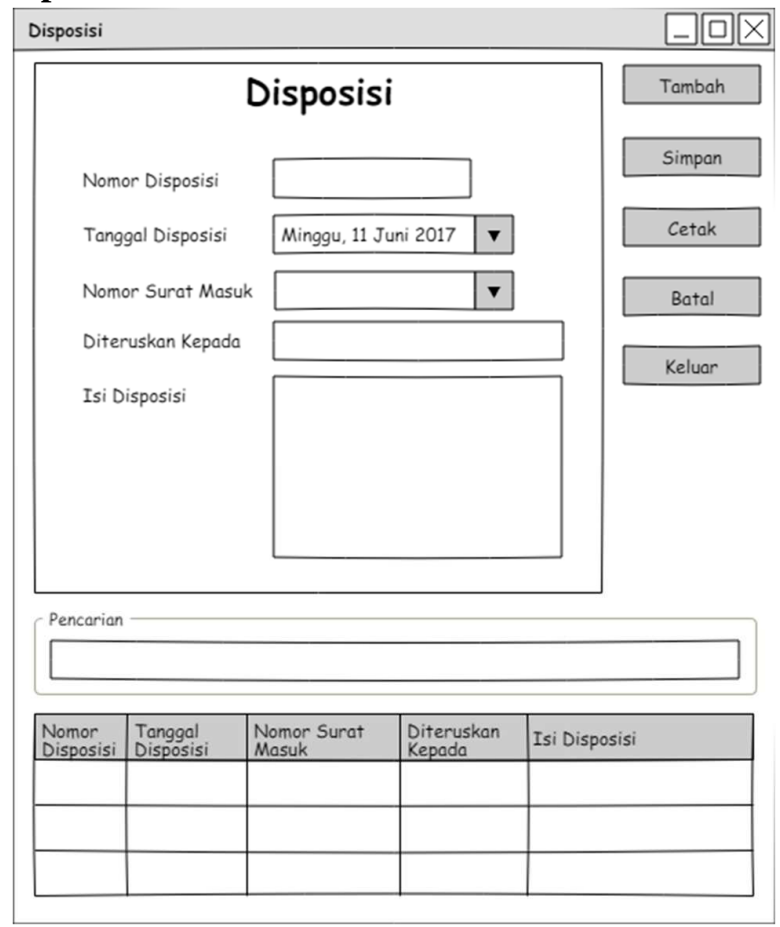

Gambar 20. Form Transaksi Disposisi

\subsection{Form Transaksi Surat Keluar}

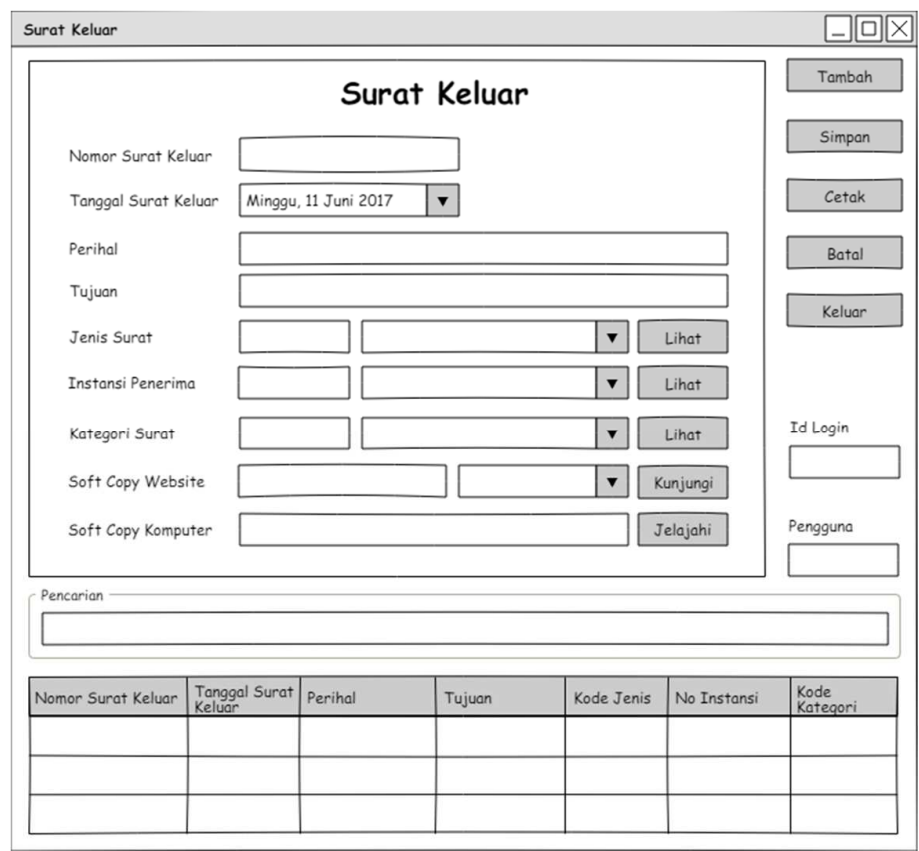

Gambar 21. Form Transaksi Surat Keluar 
3.36. Form Laporan Surat Masuk

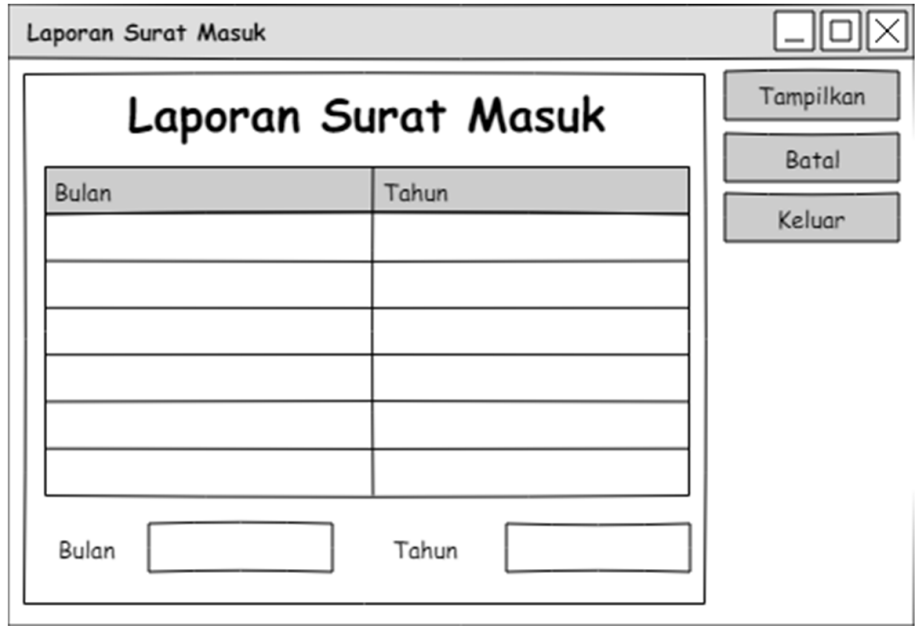

Gambar 22. Form Laporan Surat Masuk

3.37. Form Laporan Disposisi

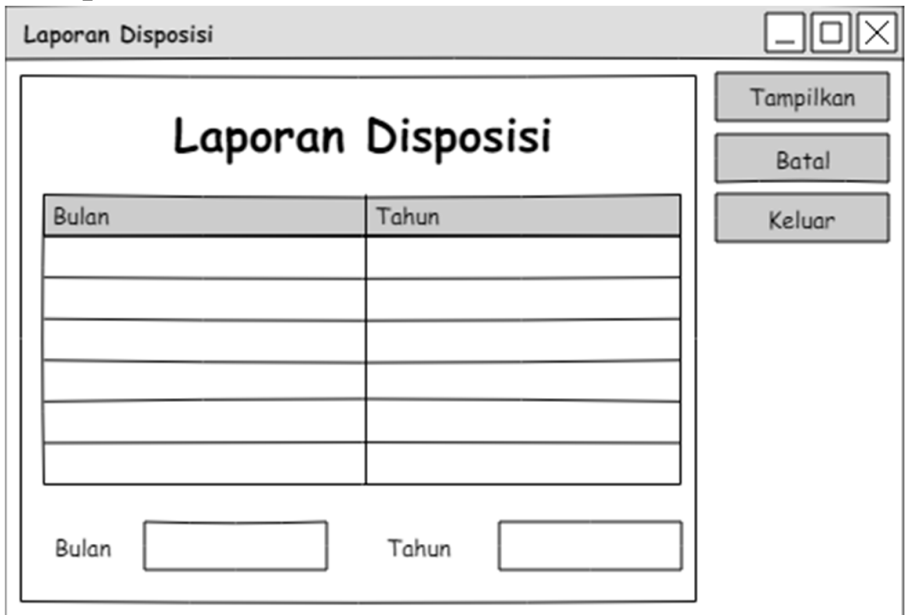

Gambar 23. Form Laporan Disposisi

\subsection{Form Laporan Surat Keluar}

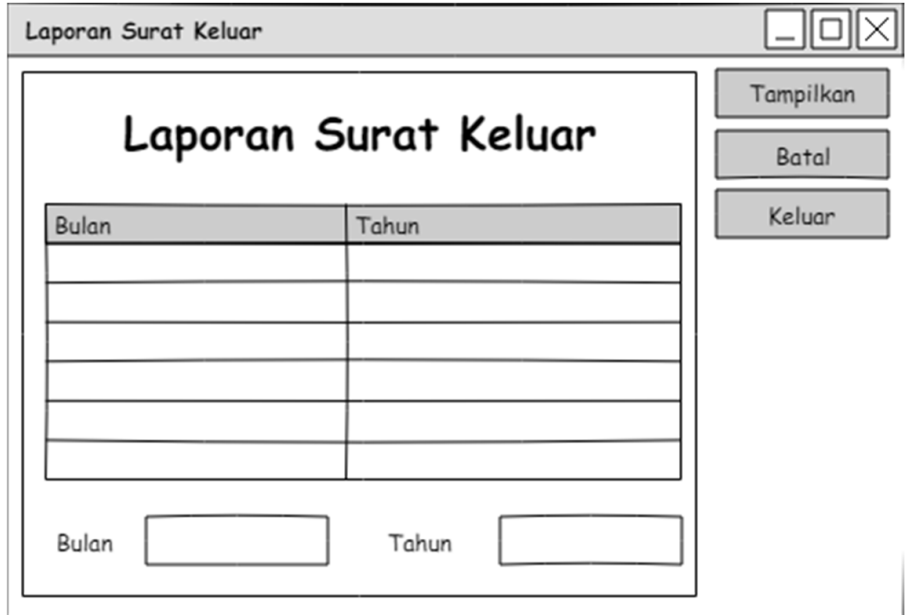

Gambar 24. Form Laporan Surat Keluar 


\subsection{Form Utilitas Ganti Password}

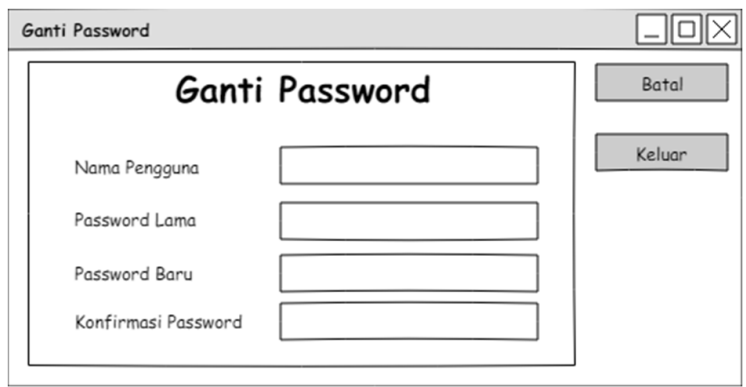

Gambar 25. Form Utilitas Ganti Password

\section{Conclusion}

Berdasarkan hasil penelitian dan pembahasan Tugas Akhir Perancangan Sistem Informasi Pengarsipan di Polsek Rancaekek maka dapat disimpulkan bahwa sistem informasi pengarsipan ini dapat mengantisipasi terjadinya kerusakan dan kehilangan data arsip, karena sistem informasi ini dapat menyimpan soft copy arsip ke beberapa situs website serta di dalam sistem komputer. Sistem informasi pengarsipan ini dapat memudahkan dalam membuat laporan jika sewaktu-waktu diperlukan. Dalam penerapan aplikasi pengembangan sistem informasi pengarsipan ini sebaiknya didukung oleh perangkat yang memadai baik dari segi pengguna maupun perangkat keras dan perangkat lunak. Hendaknya memiliki tempat penyimpanan arsip yang dibuat sesuai dengan standar tempat penyimpanan arsip yang baik dan perlu dilakukan pembersihan ruangan arsip secara berkala agar tempat penyimpanan selalu bersih dan bebas dari debu. Memasang Internet dengan kecepatan tinggi untuk mempermudah dalam menyimpan soft copy arsip di website agar data lebih aman apabila terjadi kerusakan pada sistem komputer dan lebih menghemat waktu apabila didukung oleh internet dengan kecepatan tinggi. Lebih memperhatikan lagi kegiatan penyusutan dan pemusnahan arsip agar tidak terjadi penumpukan arsip yang sudah tidak memiliki nilai guna yang berakibat mengganggu aktifitas pekerjaan.

\section{References}

[1] Amsyah, Zulkifli. (2005). Manajemen Kearsipan. Jakarta : PT Gramedia Pustaka Utama.

[2] Fathansyah. (2004). Buku Teks Komputer Basis Data. Bandung: Informatika.

[3] Fatta, Hanif Al. (2009). Analisis dan Perancangan Sistem Informasi. Yogyakarta: Andi.

[4] Gie, The Liang. (1992). Administrasi Perkantoran Modern. Yogyakarta : Liberty.

[5] Hartono, Jogiyanto. (2005). Analisis dan Desain. Yogyakarta: Andi Offset.

[6] Kusrini dan Andri Koniyo. (2007). Tuntunan Praktis Membangun Sistem Informasi Akuntansi dengan Visual Basic dan Microsoft SQL Server. Yogyakarta: Andi Offset.

[7] Kristanto, Andi. (2008). Perancangan Sistem Informasi dan Aplikasinya. Yogyakarta: Gava Media.

[8] Mulyono, Sularso dan Agung Kuswantoro. (2011). Manajemen Kearsipan. Semarang : Unnes Press.

[9] Sutanta, Edhy. (2003). Sistem Informasi Manajemen. Yogyakarta: Graha Ilmu. (2004). Sistem Basis Data. Yogyakarta: Graha Ilmu.

[10] Undang - Undang No. 7 Tahun 1971. Tentang Ketentuan-ketentuan Pokok Kearsipan.

[11] Wursanto, Ig. 1991. Kearsipan 1. Yogyakarta : Kanisius. 